\title{
Avaliação de progênies de macaúba na fase juvenil e estimativas de parâmetros genéticos e diversidade genética
}

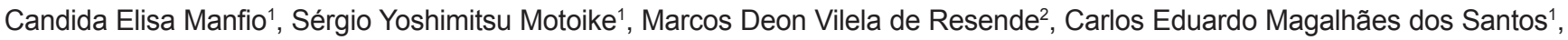 \\ Aurora Yoshiko Sato ${ }^{1}$
}

${ }^{1}$ Universidade Federal de Viçosa, Departamento de Fitotecnia, Avenida Ph Rolfs, Campus Universitário, CEP 36570-000, Viçosa, MG, Brasil

${ }^{2}$ Embrapa Florestas, Estrada da Ribeira, Km 111, CP 319, CEP 83411-000, Colombo, PR, Brasil

\author{
"Autor correspondente: \\ candidamanfio@gmail.com \\ Termos para indexação: \\ Acrocomia aculeata \\ Variabilidade genética \\ Recursos genéticos \\ Herdabilidade \\ Index terms: \\ Acroconia aculeata \\ Genetic variability \\ Genetic resources \\ Heritability
}

Histórico do artigo:

Recebido em 24 maio 201

Aprovado em 27 fev 2012

Publicado em 30 mar 2012

doi: $10.4336 / 2012 . p f b .32 .69 .63$
Resumo - A macaúba (Acrocomia aculeata) é uma palmeira oleaginosa e o extrativismo de seus frutos é de grande importância socioeconômica para os pequenos produtores rurais. O objetivo deste trabalho foi avaliar a variabilidade genética e obter informações sobre o controle genético de características morfológicas relacionadas ao crescimento e vigor da macaúba. Foram coletadas 51 progênies em Minas Gerais e São Paulo, as quais são integrantes do banco ativo de germoplasma da Universidade Federal de Viçosa. Doze meses após o plantio, essas progênies foram avaliadas quanto ao crescimento da planta $(\mathrm{cm})$ e número de folhas emitidas. Estas características apresentaram grande variabilidade entre as progênies. As estimativas dos coeficientes de herdabilidade foram de $87 \%$ e $48 \%$, para crescimento de planta e número de folhas, respectivamente, revelando controle genético e boas perspectivas para o melhoramento. O método de Tocher mostrou-se eficiente em alocar as progênies do Estado de São Paulo em um mesmo grupo. O método de seleção pelo Índice de rank médio permitiu selecionar indivíduos e progênies mais equilibrados em termos dos dois caracteres.

\section{Evaluation of macaw palm progenies in juvenile phase and estimates of genetic parameters and genetic diversity}

\begin{abstract}
The macaw palm (Acrocomia aculeate) is an extraction oil palm and its fruit is of great socioeconomic importance for small farmers. The aim of this study was to evaluate the genetic variability and to obtain information about the genetic control of morphological traits related to growth and vigor of macaw palm. Fifty-one open pollinated progenies were collected in Minas Gerais and São Paulo States, which are active members of the germplasm bank of Viçosa Federal University. These 51 progenies, twelve months after planting, were evaluated for plant growth and number of leaves emitted. The characteristics evaluated presented great variability among the progenies. Heritability coefficient of $87 \%$ and $48 \%$ were obtained for plant growth and leaf number emitted, respectively, revealing a high degree of genetic control and potential for the genetic breeding. The Tocher's method was efficient to allocate progenies from State of São Paulo in the same group. The rank index selection method allowed the selection of more balanced progenies and individuals for the two traits, making possible to optimize the selection and obtain gains in all traits simultaneously.
\end{abstract}




\section{Introdução}

A macaúba (Acrocomia aculeata) é uma palmeira oleaginosa altamente produtiva, com o segundo maior potencial entre as plantas oleaginosas, sendo superada apenas pela cultura do dendê, além de se manter produtiva por dezenas de anos (Teixeira, 2005). O cultivo da macaúba apresenta grande importância socioeconômica, pois é realizado por um grande número de pequenos produtores. No entanto, a atividade apresenta baixa produtividade devido à colheita extrativista (Wandeck \& Justo, 1988), praticada em populações com plantas heterogêneas, com idade, densidade e qualidade variáveis, fato que dificulta a aplicação de técnicas de manejo e de colheita, levando ao baixo rendimento e qualidade dos frutos (Motta et al., 2002).

O desenvolvimento de programas de melhoramento genético com esta espécie, visando aumentar a rentabilidade em termos de produção e, ao mesmo tempo, preservar e recuperar os recursos naturais, é fundamental para garantir a sustentabilidade de seu sistema de produção. Adicionalmente, pode-se obter benefícios ambientais e econômicos, servindo também como opção para sistemas agroflorestais. Costa et al. (2005) enfatizam que a avaliação do desenvolvimento inicial das progênies de espécies florestais nativas estimula o estabelecimento de um programa de melhoramento genético com germoplasma nativo, tendo em vista a aplicação de estratégias ideais, visando maximizar os ganhos genéticos das características de interesse.

Tendo em vista que um dos problemas da macaúba é o seu longo período juvenil, pois a espécie pode demorar até sete anos para o início da produção de frutos, apesar do periódo reprodutivo poder se extender por mais de 100 anos (Teixeira, 2005), estudos na fase juvenil da planta são importantes para o conhecimento da variabilidade da espécie nas fases iniciais de melhoramento.

O sucesso de um programa de melhoramento de espécies perenes depende também do conhecimento do germoplasma disponível para a obtenção do produto desejado, bem como, da variação biológica entre espécies no gênero, entre populações, dentro de espécies e indivíduos (Abreu et al., 2009). Desse modo, a estimação de parâmetros visando ao conhecimento da magnitude da variabilidade genética e a avaliação genética de indivíduos são essenciais nas várias etapas do programa de melhoramento, desde a fase de desenvolvimento inicial das mudas para efeito de seleção ao longo do programa.
Os métodos preditivos de divergência genética têm sido bastante utilizados, sobretudo pelo fato de que, ao se basearem em diferenças morfológicas e fisiológicas dos genitores, dispensam a obtenção das combinações híbridas entre eles, o que é vantajoso, especialmente quando o número de genitores cujas diversidades se deseja conhecer é elevado. Entre estes métodos, encontramos aqueles que quantificam a diversidade por meio de medidas de dissimilaridade, onde se encontra a distância de Mahalanobis e a distância euclidiana média. A distância euclidiana tem sido amplamente utilizada e pode ser estimada tomando-se por base dados sem repetições (Carvalho et al., 2003).

A análise de agrupamento apresenta a finalidade de reunir, por algum critério de classificação, os genitores em grupos, de tal forma que exista homogeneidade dentro do grupo e heterogeneidade entre os grupos, sendo adequada para identificar os genótipos divergentes e com maior probabilidade de sucesso nos cruzamentos (Cargnelutti Filho et al., 2008).

$\mathrm{O}$ método Tocher é um método de agrupamento de otimização que adota o critério de que a distância média intragrupo deve ser menor que a distância média intergrupo. Assim, como o método de agrupamento hierárquico UPGMA (média aritmética de grupos não ponderados), utiliza as médias aritméticas (nãoponderadas) das medidas de dissimilaridade, evitando caracterizar a dissimilaridade por valores extremos (mínimo e máximo) entre os genótipos considerados (Cruz, 2008).

A identificação da diversidade genética através de características morfoagronômicas é muito utilizada pelos melhoristas com a finalidade de identificar cruzamentos com potencial de se obter populações segregantes (Oliveira et al., 2008).

A diversidade genética é de grande importância para o melhoramento pois, adequadamente explorada, pode reduzir a vulnerabilidade da cultura a doenças e, ao mesmo tempo, acelerar o progresso genético para determinados caracteres (Cui et al., 2001). Quanto mais divergentes forem os genitores, maior a variabilidade resultante na população segregante, e maior a probabilidade de reagrupar os alelos em novas combinações favoráveis. A caracterização de amostras existentes em um banco de germoplasma visa possibilitar que o máximo da variabilidade genética seja reunida e preservada com o mínimo possível de duplicações, além de promover material genético para a condução de programas de 
melhoramento. No caso específico da macaúba, notase um expressivo interesse da comunidade científica, especialmente pela propriedade oleaginosa dos frutos, em relação à possibilidade de obtenção de materiais geneticamente superiores. A detecção dos melhores genótipos nativos da espécie, a fim de propiciar uma maior produtividade e especificidade dos caracteres desejados em termos comerciais, visando aumentar o rendimento da espécie através do uso de mudas e sementes melhoradas, torna-se um importante passo no aprimoramento do cultivo da espécie.

O objetivo deste trabalho foi avaliar a variabilidade genética e obter informações sobre o controle genético de características morfológicas relacionadas ao crescimento e vigor da macaúba. Avaliou-se também a divergência genética envolvendo 51 progênies de polinização aberta, visando a formação de grupos distintos.

\section{Material e métodos}

Frutos de 51 progênies (assumidas como constituídas por indivíduos meios irmãos) coletados nos estados de Minas Gerais e São Paulo (Figura 1) passaram por processo de germinação, segundo metodologia de Motoike et al. (2007). Após a obtenção das sementes pré-germinadas, o preparo das mudas foi realizado em casa de vegetação e no viveiro. Após a obtenção das mudas, o plantio foi realizado na Fazenda Experimental de Araponga, pertencente a Universidade Federal de Viçosa, no Município de Araponga, MG, e assim foi estabelecido o banco de germoplasma de macaúba da UFV.

O delineamento experimental empregado foi inteiramente ao acaso e o número de plantas variou de uma a dez plantas por progênie, de acordo com a disponibilidade de plantas para cada progênie que compõe o banco de germoplasma de macaúba. As seguintes características das plantas foram avaliadas: crescimento da planta $(\mathrm{cm})$ : obtido pela diferença da altura da planta um ano após o plantio pela altura da muda no plantio; e número de folhas emitidas por planta: obtido pelo número de folhas emitidas no primeiro ano após o plantio.

Os dados de campo foram analisados por meio da metodologia de modelos mistos, procedimento REML (Máxima Verossimilhança Restrita)/BLUP (Melhor Predição Linear não Viesada) (Resende, 2007), segundo o seguinte modelo linear.

\section{Modelo:}

$y=X b+Z a+e$, em que:

$y, b, a, e$ : vetores de dados, de efeitos fixos (média geral), de efeitos genéticos aditivos (aleatórios) e de erros aleatórios, respectivamente.

$X$ e $Z$ : matrizes de incidência para $\mathrm{b}$ e a, respectivamente.

\section{Equações de modelo misto:}

$$
\left[\begin{array}{ll}
X^{\prime} X & X^{\prime} Z \\
Z^{\prime} X & Z^{\prime} Z+A^{-1}\left(\left(1-h^{2}\right) / h^{2}\right)
\end{array}\right]\left[\begin{array}{l}
\hat{b} \\
\hat{a}
\end{array}\right]=\left[\begin{array}{l}
X^{\prime} y \\
Z^{\prime} y
\end{array}\right]
$$

Estimadores dos componentes de variância via algoritmo EM

$$
\begin{aligned}
& \hat{o}_{e}^{2}=\left[y^{\prime} y-\hat{b}^{\prime} X^{\prime} y-\hat{a}^{\prime} Z^{\prime} y\right] /[N-r(X)] \\
& \hat{o}_{a}^{2}=\left[\hat{a}^{\prime} A^{-1} \hat{a}+\dot{o}_{e}^{2} \operatorname{tr} C^{22}\right] / N_{a}
\end{aligned}
$$

em que:

$r(X)$ : posto ou número de colunas linearmente independentes de $\mathrm{X}$.

$C^{22}$ é da forma:

$$
\left(\begin{array}{cc}
C^{11} & C^{12} \\
C^{21} & C^{22}
\end{array}\right)=\left(\begin{array}{cc}
X^{\prime} X & X^{\prime} Z \\
Z^{\prime} X & Z^{\prime} Z+A^{-1} \sigma_{e}^{2} / \sigma_{a}^{2}
\end{array}\right)^{-1}
$$

$N_{a}$ : número de elementos aleatórios (indivíduos).

A: matriz de parentesco genético aditivo.

tr: operador traço matricial, dado pela soma dos elementos da diagonal da matriz.

$N$ : número total de dados.

Utilizou-se a análise multivariada, aplicando-se as técnicas de agrupamento. Na técnica de agrupamento, foi utilizada a distância euclidiana média como medida de dissimilaridade, e na delimitação dos grupos, o método Tocher e UPGMA, para estabelecer um dendograma que pudesse identificar grupos de genótipos. Foram utilizados os softwares Selegen-Reml/Blup - versão 2009 (Resende, 2002, 2007) e GENES - versão 2009 (Cruz, 2001) para realização das análises estatísticas. Progênies superiores foram também identificadas pelo índice de rank médio, adaptado de Mulamba e Mock (1978). 


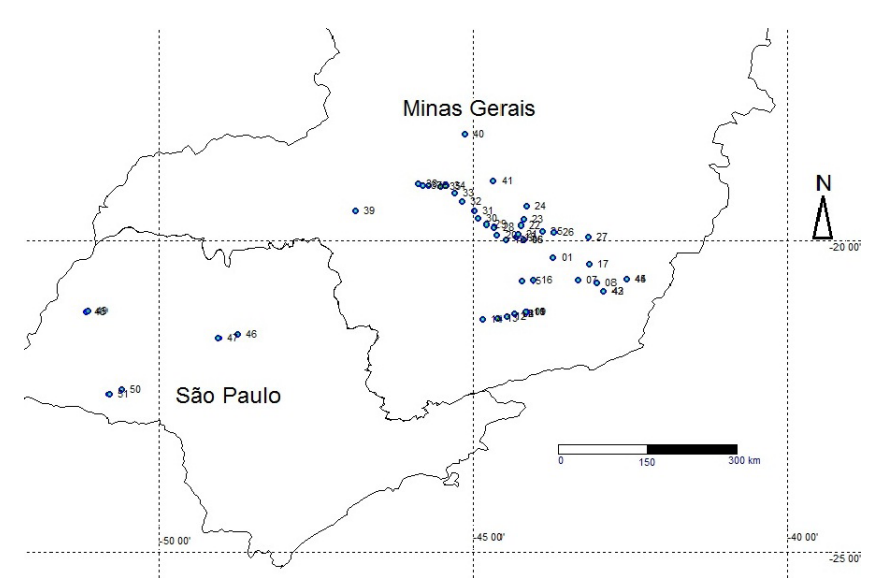

Figura 1. Mapa do local de coleta das procedências das progênies de macaúba utilizadas para análise de diversidade (progênies 01 a 45 coletadas em Minas Gerais, progênies 46 a 51 coletadas em São Paulo).

\section{Resultados e discussão}

Os resultados revelaram a presença de variabilidade genética de alta magnitude entre as 51 progênies para as duas características avaliadas, conforme corroborado pelas estimativas do coeficiente de variação genética (Tabela 1). Santos et al. (2008) evidenciam que a ocorrência de variabilidade é condição essencial para o estabelecimento de um programa de melhoramento genético e deve ser explorada com vistas a obtenção de características agronomicamente favoráveis.

As estimativas de variância residual foram de baixas magnitudes, conforme corroborado pelas estimativas do coeficiente de variação residual (Tabela 1) para as duas características. Os valores do coeficiente de variação relativa $(\mathrm{CVr} \%)$ encontrados foram de 2,66 e 0,97 para altura da planta e número de folhas, respectivamente. Valores desse coeficiente maiores ou iguais a 1 revelam uma situação muito favorável para a seleção (Vencovsky e Barriga, 1992). Assim, o experimento está adequado para proporcionar uma precisa inferência sobre o valor genotípico das progênies.

Devido à ampla variabilidade existente entre as progênies estudadas, foram obtidos altos coeficientes de herdabilidade individual no sentido restrito, $87 \%$ e $48 \%$, para crescimento de planta e número de folhas emitidas pela planta, respectivamente. Este parâmetro indica a possibilidade de seleção de genótipos promissores de macaúba, que pode ser utilizados em estudos futuros de melhoramento da espécie ou para servirem de fonte inicial de sementes para plantios.
Para o início de um programa de melhoramento, a seleção das populações a serem trabalhadas deve ser em relação a caracteres relacionados ao produto de interesse, no caso das oleaginosas, o óleo. Para macaúba, apesar de escassas as referências às características de produção, sabe-se que estas podem estar correlacionadas com caracteres vegetativos analisados na fase juvenil, assim como ocorre para o açaí (Farias Neto et al., 2005; Nogueira et al., 2004). Desta forma, essas estimativas de parâmetros genéticos para características relacionadas ao vigor da planta são subsídios importantes para o melhoramento da macaúba.

Tabela 1. Estimativas de parâmetros genéticos obtidos da análise de 51 progênies do banco ativo de germoplasma de macaúba da UFV, aos 12 meses de idade, para as características: crescimento da planta $(\mathrm{CP})$, e número de folhas emitidas por planta (NFP).

\begin{tabular}{ccc}
\hline Parâmetros* $^{*}$ & $\mathbf{C P}(\mathbf{c m})$ & NFP (unidade) \\
\hline $\mathrm{Va}$ & 551,45 & 0,75 \\
$\mathrm{Ve}$ & 77,95 & 0,80 \\
$\mathrm{Vf}$ & 629,40 & 1,55 \\
$\mathrm{~h}^{2}$ & $0,87 \pm 0,29$ & $0,48 \pm 0,22$ \\
$\mathrm{CVa} \%$ & 31,26 & 17,56 \\
$\mathrm{CVe} \%$ & 11,75 & 18,14 \\
$\mathrm{CVr} \%$ & 2,66 & 0,97 \\
Média & 75,11 & 4,93 \\
\hline
\end{tabular}

* Va: variância genética aditiva individual; Ve: variância residual; Vf: variância fenotípica individual; $\mathrm{h}^{2}$ : herdabilidade individual no sentido restrito; $\mathrm{CVa} \%$ : coeficiente de variação genética aditiva individual; $\mathrm{CVe} \%$ : coeficiente de variação residual; $\mathrm{CVr}=\mathrm{CVa} / \mathrm{CVe}=$ coeficiente de variação relativa.

A existência de variabilidade genética entre as progênies para os dois caracteres permitiu separá-las pelo método de Tocher em sete grupos (Tabela 2), considerando simultaneamente os dois caracteres por meio dos valores genéticos preditos das progênies. O primeiro grupo foi formado por 35 progênies, dois grupos com seis progênies cada, e quatro grupos com apenas uma progênie. O grupo III é formado por todas as progênies (46 a 51) de São Paulo. Os agrupamentos foram relacionados com as origens geográficas das progênies. Estes resultados corroboram com Abreu et al. (2009) que estudou a variabilidade de 10 acessos de pinhão-manso em relação às características juvenis da planta pelo método Tocher. 
Tabela 2. Grupos de similaridade genética obtidos a partir das 51 progênies de macaúba estabelecidos pelo método de Tocher, baseado na distância euclidiana média.

\begin{tabular}{cc}
\hline Grupo & Progênies \\
\hline I & 12345678911121314161719212224 \\
& 25262728293032333435384041424345 \\
II & 101823313944 \\
III & 464748495051 \\
IV & 37 \\
V & 20 \\
VI & 15 \\
VII & 36 \\
\hline
\end{tabular}

O método do UPGMA formou quatro agrupamentos utilizando $70 \%$ de dissimilaridade. Três grupos com mais de 14 progênies e um com apenas quatro progênies. O primeiro grupo foi formado por todas as progênies do estado de São Paulo e algumas de Minas Gerais (Tabela 3).

Trabalhos com macaúba utilizando técnicas moleculares (Bellon et al., 2009; Oliveira et al., 2008) e o método UPGMA também observaram uma tendência de agrupamento conforme a origem geográfica.

Tabela 3. Grupos de similaridade genética entre 51 progênies de macaúba estabelecidas pelo método de UPGMA, baseado na distância euclidiana média.

\begin{tabular}{cr}
\hline Grupo & Progênies \\
\hline I & 28121718282945464748495051 \\
II & 13479111314151921222324262744 \\
III & 10303139 \\
IV & 561620253233343536373840414243 \\
\hline
\end{tabular}

Os métodos utilizados agruparam as progênies com tendência da origem geográfica comum. Entretanto, os grupos formados não foram coincidentes pelos diferentes métodos. O método de Tocher aplicado sobre valores genéticos preditos das progênies mostrou-se mais eficiente em alocar somente as progênies do Estado de São Paulo em um mesmo grupo. Esta separação em grupos distintos é importante para o melhoramento genético da espécie, pois a partir destes agrupamentos pode ser obtida a heterose para os caracteres quantitativos de interesse econômico quando se cruzar progênies pertencentes a diferentes grupos.

O método de seleção pelo Índice de rank médio permite selecionar indivíduos e progênies mais equilibrados em termos dos vários caracteres. Isso permite otimizar a seleção e obter ganhos em todos os caracteres simultaneamente.

A avaliação pelo Índice de rank médio, adaptado de Mulamba e Mock (1978) evidenciou ganhos genéticos nas características avaliadas para as progênies (Tabela 4). Os ganhos com a seleção das 25 melhores progênies foram de $32,71 \%$ para crescimento de planta e $36,31 \%$ para número de folhas emitidas por planta. As 25 progênies selecionadas na análise foram: 20, 16, 36, 9, 31, 26, 29, 12, 5, 39, 14, 21, 28, 3, 25, 4, 10, 34, 22, $48,51,6,35$ e 38 , sendo duas (48 e 51) procedentes do Estado de São Paulo.

Tabela 4. Ganho genético esperado nas características avaliadas com a seleção de progênies de macaúba, praticada com base no índice rank de Mulamba e Mock (1978).

\begin{tabular}{lc}
\hline Características & $\begin{array}{c}\text { GS\% } \\
\text { Ganho com seleção }\end{array}$ \\
\hline Crescimento da planta & 32,71 \\
Número de folhas da planta & 36,31 \\
\hline
\end{tabular}

\section{Conclusões}

Houve variabilidade genética entre as 51 progênies de macaúba para as características número de folhas por planta e crescimento da planta.

As características avaliadas apresentaram coeficientes de herdabilidade no sentido restrito de elevada magnitude, revelando controle genético e boas perspectivas para o melhoramento.

Os métodos utilizados agruparam as 51 progênies em sete e quatro grupos, pelo método de agrupamento de Tocher e UPGMA, respectivamente.

O método de seleção pelo Índice de rank médio permitiu selecionar indivíduos e progênies mais equilibrados em termos dos dois caracteres.

\section{Agradecimentos}

Ao apoio financeiro da Fapemig. 


\section{Referências}

ABREU, B. F.; RESENDE, M. D. V. de; ANSELMO, J. L.; SATURNINO, H. M.; BRENHA, J. A. M.; FREITAS, F. B. Variabilidade Genética entre subamostras de pinhão-manso na fase juvenil. Magistra, Cruz das Almas, BA, n. 21, p. 36-40, 2009.

BELLON, G.; FALEIRO, F. G.; CARGNIN, A.; JUNQUEIRA, N. T. V.; SOUZA, L. S. de; FOGAÇA, C. M. Variabilidade genética de acessos de macaúba (Acrocomia aculenta) com base em marcadores RAPD. In: CONGRESSO BRASILEIRO DE MELHORAMENTO DE PLANTAS, 5., 2009, Guarapari. Anais... Vitória: Incaper, 2009.

CARGNELUTTI FILHO, A.; RIBEIRO, N. D.; REIS, R. C. P.; SOUZA, J. R.; JOST, E. Comparação de métodos de agrupamento para o estudo da divergência genética em cultivares de feijão. Ciência Rural, Santa Maria, RS, v. 38, p. 2138-2145, 2008.

CARVALHO, L. P. de; LANZA, M. A.; FALLIERI, J.; SANTOS, J. W. dos. Análise da divergência genética entre subamostras de banco ativo de germoplasma de algodão. Pesquisa Agropecuária Brasileira, Brasília, DF, v. 38, p. 1149-1155, 2003.

COSTA, R. B.; RESENDE, M. D. V. de; CONTINI, A. Z.; REGO, F. L. H.; ROA, R. A. R.; MARTINS, W. J. Avaliação genética dentro de progênies de erva-mate (Ilex paraguariensis St. Hil.), na região de Caarapó, MS, pelo procedimento REML/BLUP. Ciência Florestal, Santa Maria, RS, n. 15, p. 371-376, 2005.

CRUZ, C. D. Programa GENES: versão Windows: aplicativo computacional em genética e estatística. Viçosa, MG: UFV, 2001. 648 p.

CRUZ, C. D. Programa GENES: diversidade genética. Viçosa, MG: UFV, 2008. 278 p.

CUI, Z.; THOMAS, E.; CARTER, JR.; JOSEPH, W. B.; RANDY, W. Phenotypic diversity of modern Chinese and North American soybean cultivars. Crop Science, Madison, WI, n. 41, p. 1954-1967, 2001.

FARIAS NETO, J. T.; OLIVEIRA, M. S. P.; MULLER, A. A.; NOGUEIRA, O. L.; ANAISSI, D. F. S. P. Variabilidade genética em progênies jovens de açaizeiro. Cerne, Lavras, MG, n. 11, p. 336-341, 2005.

MOTTA, P. E.; CURI, N.; OLIVEIRA-FILHO, A. T.; GOMES, J. B. V. Ocorrência de macaúba em Minas Gerais: relação com atributos climáticos, pedológicos e vegetacionais. Pesquisa Agropecuária Brasileira, Brasília, DF, v. 37, p. 1023-1031, 2002.
MOTOIKE, S. Y.; LOPES, F. A.; SÁ JUNIOR, A. Q. de; CARVALHO, M.; OLIVEIRA, M. A. R. de. Processo de germinação e produção de sementes pré-germinadas de palmeiras do gênero Acrocomia. A01C 1/00; A01C 14/00. PI0703180-7. 20 jul. 2007.

MULAMBA, N. N.; MOCK, J. J. Improvement of yield potential of the Eto Blanco maize (Zea mays L.) population by breeding for plant traits. Egyptian Journal of Genetics and Cytology, Alexandria, n. 7, p. 40-51, 1978.

NOGUEIRA, O. L.; GALVÃO, E. U. P.; OLIVEIRA, R. P. de; MOREIRA, D. A. Relações entre caracteres fenotípicos quantitativos e a produção de palmito de açaizeiro (Euterpe oleraceea Mart.). In: MOURÃO, L.; JARDIM, M. A.; GROSSMANN, M. Açai: possibilidade e limites em progressos de desenvolvimento sustentável no estuário amazônico. Belém: CEJUP, 2004. p. 27-36.

OLIVEIRA, D. A.; MELO JÚNIOR, A. F.; BRANDÃO, M. M.; RODIRGUES, L. A.; FONSECA, F. S. A. da; FERREIRA, M. F. M.; SILVA, G. M. Diversidade genética de populações de Acrocomia aculeata (Jacq.) Lodd. (Arecaceae) no norte de estado de Minas Gerais. In: SIMPÓSIO NACIONAL DO CERRADO, 9.; SIMPÓSIO INTERNACIONAL SAVANAS TROPICAIS, 2., 2008. Brasília, DF. Anais... Planaltina, DF: Embrapa Cerrados, 2008.

RESENDE, M. D. V. de. Matemática e estatística na análise de experimentos e no melhoramento genético. Colombo: Embrapa Florestas, 2007. 435 p.

RESENDE, M. D. V. de. Genética biométrica e estatística: no melhoramento de plantas perenes. Brasília, DF: Embrapa Informação Tecnológica, 2002. 975 p.

SANTOS, C. E. M. dos; PISSIONI, L. L. M.; MORGADO, M. A. D.; CRUZ, C. D.; BRUCKNER, C. H. Estratégias de seleção em progênies de maracujazeiro-amarelo quanto ao vigor e incidência de verrugose. Revista Brasileira de Fruticultura, Jaboticabal, n. 30, p. 444-449, 2008.

TEIXEIRA, L. C. Potencialidades de oleaginosas para produção de biodiesel. Informe Agropecuário, Belo Horizonte, n. 26, p 18-27, 2005.

VENCOVSKY, R.; BARRIGA, P. Genética biométrica no fitomelhoramento. Ribeirão Preto: Sociedade Brasileira de Genética, 1992. 486 p.

WANDECK, F. A.; JUSTO, P. G. A macaúba, fonte energética e insumo industrial: sua significação econômica no Brasil. In: SIMPÓSIO SOBRE O CERRADO, SAVANAS: ALIMENTO E ENERGIA, 6., 1988, Planaltina. Anais... Planaltina: EMBRAPACPAC, 1988. p. 541-577. 